\title{
Addressing Student Diversity and Integrative Learning in an Undergraduate Medical Curriculum
}

\author{
Shalote R. Chipamaunga* (), Detlef R. Prozesky \\ Department of Health Professions Education and Student Support, Faculty of Medicine and Health Sciences, \\ University of Zimbabwe, Harare, Zimbabwe \\ Email: *src@pcbillc.com, *schipamaunga8@gmail.com
}

How to cite this paper: Chipamaunga, S.R. and Prozesky, D.R. (2021) Addressing Student Diversity and Integrative Learning in an Undergraduate Medical Curriculum. Open Access Library Journal, 8: e7252.

https://doi.org/10.4236/oalib.1107252

Received: February 18, 2021

Accepted: April 23, 2021

Published: April 26, 2021

Copyright $\odot 2021$ by author(s) and Open Access Library Inc.

This work is licensed under the Creative Commons Attribution International License (CC BY 4.0).

http://creativecommons.org/licenses/by/4.0/

\begin{abstract}
South African universities are increasingly enrolling students from a variety of educational backgrounds. This brings in diversity in levels of language and learning ability and universities face the challenge of adjusting their curricula to meet the academic needs of the different learners. This paper documents our experiences and those of students and teachers on a course that we introduced at a university in South Africa to address student diversity and integrative learning in a higher institution of learning. A five-pronged, spiralling, examinable course entitled "Medical Thought and Practice" was explicitly designed to address integrative learning for a diverse student body in medical education. Five components were designed to address preparation for and practice in integrative learning. These were: "Learning and Language", "Logic and Critical Thinking", "Medical Terminology", "Integrating Problems" and "Health Systems Dynamics". The methods we used to gather students" reflections reported in this paper were two-fold. Firstly, a student feedback questionnaire was administered to all first-year students at the end of the first and second semesters when the course was first introduced. Secondly, pertinent students' reflections were extracted from in-depth interviews and focus group discussions during the $4^{\text {th }}$ and $5^{\text {th }}$ years of implementation of the course. Most students' experiences with the value of the course in enabling integrative learning were positive, increasingly so as their exposure to it increased. Some students reported that they acquired lifelong skills in critical thinking, problem solving and the ability to integrate material from different sources.
\end{abstract}

\section{Subject Areas}

Medical Education 


\section{Keywords}

Student Diversity, Integrative Learning, Undergraduate Medical Program, Logic and Critical Thinking, Health Systems Dynamics, Learning and Language

\section{Introduction}

In undergraduate medical programmes there is a clear logic in seeing horizontal and vertical integration of content as a good in itself. Several educational theorists like Bloom, Gagne and Ausubel have written extensively in support of integration and integrative learning. In this context integration is taken to mean that students learn information from many different disciplines. They must be able to bring this information together as they start carrying out the principal activity of their professional lives, the doctor-patient consultation. This is emphasised in the call from "Tomorrow's Doctors" in 1993 for integration of basic physical, biological and behavioural sciences with early clinical exposure [1]. Similarly the Health Professions Council states that doctors should be able to "Reflect on, integrate, apply and evaluate core knowledge, skills, attitudes and character acquired during undergraduate training" (Enabling Competency 1.2.1a), "integrating information to make differential diagnoses and propose holistic management plans" (Enabling Competency 1.3.1e), and "integrating new learning with practice" (Enabling Competency 6.1.1e) [2]. To some degree the ability to learn to integrate knowledge ("integrative learning") is likely to be intuitive in all humans, as a survival strategy for life. However, students from diverse educational backgrounds will not have developed this ability to the same degree by the time they enter medical programmes-those in whom it is less developed are likely to struggle academically as they are soon called upon to integrate their knowledge in assessments and at the bedside.

In the context of this paper, student diversity refers to the differences in educational background, culture and language with which students come to university. Such diversity was experienced in South Africa in the years immediately following the 1994 transition from the apartheid era. Universities which had previously catered largely for students from advantaged backgrounds, mostly whites, were mandated to open their doors to those from previously disadvantaged backgrounds, mostly black [3]. As a result South African universities experienced an increasing number of students who arrived without the requisite study skills and strategies required for succeeding in higher education [4] [5]. Student diversity may impact on different aspects such as variations in academic and English language skills; study skills; confidence to participate; numeracy; and motivation to study [6] [7] [8]. The resulting alienation that black students experience in historically white universities is mentioned by Adam Habib [9]. So, for example, adjusting to a medical school environment has been reported as 
a potential cause of distress [10]; this distress would be particularly acute for students from remote rural backgrounds who are not familiar with the urban setting in which most universities are located. However the transformation of South African universities to accommodate diverse groups of students has been slow [11]. It seems that universities have maintained an implicit assumption that the diverse groups of students are homogenous in terms of levels of preparedness and ability to handle university studies [12]. As explained above this may in turn have a negative impact on their ability to integrate information from different sources when they need to do so.

With reference to current studies in higher education institutions, Kelly observes that student-oriented support services and academic interventions are now receiving attention [13]. There is a clear need to creating a nurturing learning environment [10]. Some form of support is needed to enable students cope with the language of instruction while developing skills to identify links between subjects is necessary at the beginning of a demanding programme like Medicine. According to Sfard, participation describes collaborative knowledge production where learning is reconfigured and knowledge is reconceptualised [14] [15]. This emphasis on social interactions necessitates the teaching of language to enable communication amongst students from different backgrounds. Students report that the ability to integrate learning develops over time and it is heavily influenced by factors in the environment [16]. Students play a role in making integration happen but this needs the support of a curriculum that is committed to assisting them to integrate learning. Authorities in educational psychology support the idea of scaffolding to guide students through periods that are perceived problematic until they can learn independently [17] [18] [19]. The theoretical underpinning of Zone of Proximal Development by Vygotsky supports scaffolding [20].

Examples of and suggestions for integrated curricula have been presented, starting with encouraging dialogue between and amongst disciplines and culminating in fully integrated teaching [21] [22] [23] [24]. However the nature of support to enable students to integrate is still an open question-what it looks like and how it might be shaped by emerging cultural realities and new thinking about learning and teaching [25]. One example concerns reading with comprehension and critical thinking, which are key skills that determine success at university level. There is evidence that most first year university students lack academic reading skills and employ reading strategies that result in surface learning [26] [27]. Studies on reading abilities found that second language readers struggle with unknown words and phrases resulting in poor understanding; on the other hand first language readers were successful in reading with understanding while integrating new information with old [28]. Since there is a close link between unfamiliar vocabulary and slow reading, students who were taught reading strategies understood passages better [29]. Integrative learning could also promote structures, strategies, and activities that bridge the divide between 
learning experiences inside and outside the classroom, theory and practice, and disciplines and fields [30].

While it must, to some degree be intuitive, the ability to integrate knowledge needs to be explicitly developed to reach its full potential. This is particularly true of students from relatively disadvantaged educational backgrounds, for example those for whom the main study strategy has been rote learning resulting in superficial retention of information. At university level, "deep" learning through participation becomes imperative. Integration is a key element in the desirable "deep" learning [31]. There is a dearth of information in the literature about interventions in medical programmes explicitly designed to promote integrative learning, while also meeting the needs of a diverse spectrum of students.

\section{Methods}

In this paper, we share our experiences of an intervention that we introduced. The methods we used to gather students' reflections reported in this paper were two-fold. Firstly, a student feedback questionnaire was administered to all first-year students at the end of the first and second semesters when the course was first introduced. Secondly, some pertinent students' reflections were extracted from a $\mathrm{PhD}$ phenomenographic study in-depth interviews and focus group discussions during the $4^{\text {th }}$ and $5^{\text {th }}$ years of implementation of the course. Phenomenography is a research approach which is particularly aimed at questions of relevance to learning and understanding in an educational setting [32].

\section{The Interventionn}

In this paper, we document our experiences implementing a two-year course that we introduced as an early intervention in a medical school to support and develop the ability to integrate, which in addition takes student diversity into account. Each component of the resulting two-year course is described and the logic behind its inception and implementation is explained. The paper also reports students' response to the intervention. It is hoped that sharing such innovations will influence learning that is designed intentionally to help students cope better with integrative learning. It should be noted that this paper does not attempt to evaluate the intervention but rather documents this unique effort to share with others. The intervention addresses two issues that are of concern in medical education. We have not come across efforts that address student diversity together with assisting students to integrate learning elsewhere in our subsequent experiences.

\subsection{The Intervention: Background and Rationale}

In 2004 the undergraduate medical program at a university in South Africa changed from a traditional six-year program (pre-clinical courses followed by clinical ones). The new programme made provision for two streams of entry, with some students entering into the first year directly from high school and 
others entering as graduates into the third year. From the third year onwards problem-based learning was the main educational strategy-a prime example of integrative learning. However, the first two years of the programme were still subject based, with Year 1 consisting of separate physical, biological and behavioural science courses (the latter as electives) and Year 2 consisting of separate courses in Anatomy, Physiology and Molecular Medicine. Ideally the first two years should have been revised before embarking on the radical and ambitious changes to later years. However, the need for a thorough revision now became clear, to remediate a number of observed defects in the medical programme overall, and in the first two years in particular. Following wide consultation and many discussions these were identified as:

1) Inadequate grounding in Psychology and Medical Sociology.

2) Basic sciences (Physics, Chemistry, Biology, Mathematics) were taught in the abstract without linking them to biomedical processes.

3) A lack of intentional measures to assist students from relatively deprived academic backgrounds to attain the level of language, reasoning and integrative ability that more favoured students already had.

4) No concrete steps taken to integrate the learning in different subjects to each other and with the following years in the programme-in stark contrast to Years 3 and 4, the "problem-based learning" years.

The Health Professions Council of South Africa accreditation team in its previous visit pointed to the lack of integration in Years 1 and 2 and directed that this be addressed. Concrete steps were taken with respect to the first and second years of the programme. This article however deals with a course that was introduced to deal with the third and fourth deficiencies: to assist students (especially those from relatively deprived academic backgrounds) to attain necessary levels of language and reasoning, and to promote integrative learning in all students. The innovation was a course we called "Medical Thought and Practice", locally referred to as "MTP". It was introduced in Year 1 of the medical undergraduate programme in 2010 and in Year 2 in 2011. The course was designed to be a spiral one over two years, with the more advanced second year course building on the more basic first year course. The 2010 cohort of medical students consisted of $60 \%$ black, $6 \%$ coloured (mixed race), 12\% Indian and 21\% white. According to the South African socio-economic demographics, $60 \%$ of the class were potentially disadvantaged. Therefore, although the innovative course was meant for all the students, the majority of the class stood to benefit more.

\subsection{Components of the Intervention: "Medical Thought and Practice" Course}

A two-year course was introduced and in each of its two years the new course had five units. Three of these attempted to deal with diversity by teaching higher cognitive skills that are needed for university level courses (and therefore also for integration); the other two taught real skills in integrating material from differ- 
ent subject areas. The first three units were taught in the first half of the year while the remaining two were taught in the second half. The rationale for this sequence was to develop the higher cognitive skills followed by application in practicing integration. Together the five units are shown in Figure 1: The five units of the "Medical Thought and Practice" course.

Of the five units some have also been used in other medical programmes-e.g. "Learning and Language" and "Medical Terminology" [12] [17] [18]. What is unique about the "Medical Thought and Practice" course is its five-pronged approach to address medical student diversity and to teach integrative skills intentionally, as a formal examinable course.

\subsubsection{Health System Dynamics}

"Health System Dynamics" made up 50\% of the Medical Thought and Practice course. As its name implies "Health System Dynamics" focuses on systems and how they function; it incorporates thinking, modelling, computer-based simulation and more thinking. The unit was introduced to enable students to understand the ubiquitous systems in the medical field and how they function and interact. Experience has shown that some students struggle with conceptualising systems fully and this is linked to their educational background [33]. "Health System Dynamics" has the potential to teach students a lifelong way of thinking and problem solving while promoting horizontal and vertical integration of learning [34]. Student performance in the unit was assessed by means of practical examinations in the computer laboratory as well as a theory paper.

\subsubsection{Learning and Language}

The rationale for introducing this unit was the observation that many students failed to progress in their studies effectively simply because they did not possess the cognitive skills and language to learn and study effectively [4]. Psychology has linked performance of some medical errors to shame and guilt which may be

\begin{tabular}{|c|c|}
\hline $\begin{array}{c}\text { Intentional preparation for } \\
\text { higher learning and integration }\end{array}$ & Practising integration \\
\hline $\begin{array}{ll}\text { Learning and Language } \\
\text { - } & \text { English language skills } \\
\text { - } & \text { Reading and writing skills } \\
\text { - } & \text { Study skills }\end{array}$ & $\begin{array}{l}\text { Integrating Problems and Exercises } \\
\text { - Scenarios demonstrating integration } \\
\text { - Exercises to integrate material from } \\
\text { different subjects }\end{array}$ \\
\hline $\begin{array}{l}\text { Medical Terminology } \\
\text { - The Latin and Greek roots of components of } \\
\text { medical terms } \\
\text {-Analysing longer terms to determine their } \\
\text { meaning }\end{array}$ & $\begin{array}{l}\text { Health System Dynamics } \\
\text { - Systems and how they function } \\
\text { - Demonstrating how system components } \\
\text { interact and integrate } \\
\text { - Modelling and computer-based simulation } \\
\text { - A lifelong way of thinking about reality and } \\
\text { solving problems }\end{array}$ \\
\hline
\end{tabular}

Figure 1. The five units of the "medical thought and practice" course. 
a result of failure to communicate effectively [35]. In this unit, students were introduced to strategies for reading at the correct speed and with understanding to cope with academic work at university level. The "Learning and Language" component was particularly relevant to students whose comprehension of the English language was not strong enough to enable deep understanding of school content, and to hold academic conversations with their contemporaries. This unit helped students acquire skills they needed to be successful in all their subjects in the early and later years of their studies. Student performance in the unit was assessed by means of practical assignments.

\subsubsection{Logic and Critical Thinking}

The aim of this unit was to help students learn to draw correct conclusions from facts. Students were taught to apply terms, propositions and syllogisms thus enriching their vocabulary. The unit was introduced because all science is constructed empirically; scientists observe events in the natural world and need to draw the correct conclusions from them [36]. Experience has shown that teachers regularly encounter the failure of students to reason logically from facts, and to identify flaws in their own thinking (which also raises the question why formal teaching of logic for medical students was largely abandoned at Oxford University in the middle of the $19^{\text {th }}$ Century) [37]. There is documentation linking this "failure of logic" to medical errors related to diagnosing and treatment of patients [38]. The unit was taught by teachers from the Philosophy Department (which places itself in the analytic philosophy tradition where logic has an integral place) who guided students in applying key concepts of logic in analysing scenarios doctors encounter in medicine. Like the "Learning and Language", this unit was also particularly relevant to students with a weak academic background. The unit was assessed by means of a written examination.

\subsubsection{Medical Terminology}

This unit aimed to help students master scientific and biological/medical jargon more effectively. Since formal teaching of classical languages for medical students was abandoned years ago many students struggle to learn long words derived from Latin and Greek [39]. If students know the component words (prefixes, suffixes and combining forms) on which these terms are based it is easier to work out what the terms mean and to learn them. In line with constructivism, in particular Piaget, learning takes place when students construct new knowledge (complex medical terms) out of their previous experiences (the root words) [40]. This also facilitates integration with other subjects since the Latin and Greek core words are found in different physical, biological, and medical science disciplines. We reasoned that students with a weak academic background would find this unit particularly helpful as the integration of core word components facilitates learning. The unit was also assessed by means of a written examination.

\subsubsection{Integrating Problems and Exercises}

The aim of this unit was to show students that everything they learn in the Year 
1 and Year 2 relates to the practice of medicine and therefore to what they will be learning in later years in their programme ("vertical integration"). There is abundant evidence that students learn "within boxes" and are subsequently unable to bring knowledge from different subjects together, so they need knowledge of several disciplines to deal with one case or problem ("horizontal integration") [41]. In this unit, students were presented with regular examples showing how the basic physical, biological, and behavioural sciences all contribute to understanding medical cases. This was followed by practical assignments for each student based on mini-case scenarios, in which they were expected to link their basic science learning to the medical scenario. For example, students were able to understand that Boyle's law explains the mechanism of respiration. This not only promoted horizontal and vertical integration but introduced students to basic aspects of clinical medicine. The practical assignments constituted the assessment of the unit.

\section{Evidence of the Effects of the Course}

To us, the team developing and then implementing the innovative MTP course, the reasoning behind introducing its five components was clear. There is internal logic to each of the five components and the literature, student comments and qualitative findings from the phenomenographic study is all additional data we have, to bolster the evidence of the effects of the course. We did not plan to evaluate its effectiveness by comparing the knowledge and skills in the five areas of students in cohorts before the course was introduced, with those of students who had undergone it (which would have been ideal). Instead, the standard procedure of obtaining student feedback from the first new cohort was undertaken. In addition, relevant student reflections from a detailed subsequent phenomenographic study on integration of learning are presented as further evidence of the effects of the course. Data were extracted from a phenomenographic study which used the anatomy of awareness framework for analysis [16]. Additionally, we think Kirkpatrick's idea is a useful framework here. The student feedback data are at level 1 only-the "participant response" and the phenomenographic data provide partial, self-reported data about levels 2 and 3 [32].

We think the course is a worthy innovation to be presented to academic colleagues in similar situations and we have given what evidence we have in support of its usefulness.

\subsection{Student Feedback (Mid-Term and End-of-Year)}

At the end of the first semester of the first year, most of the units designed for preparation for higher learning and integration had been presented and we solicited students' feedback the rubric in Table 1 . Students were asked to rate each statement with a "yes" or "no".

The results for students giving a rating of "yes" are given in Figure 2: Student feedback on units at mid-term. 
Table 1. Rubric for feedback.

\section{Feedback statement}

1) I have learnt some new things that I did not know before.

2) I will use what I learnt in my day to day life.

3) I will use what I learnt in other units and courses of this year.

4) I will use what I learnt in my further studies next year.

5) What I have learnt from this unit will help me draw conclusions from facts.

6) What I have learnt in this unit will help me understand all the other subjects in this year and later years.

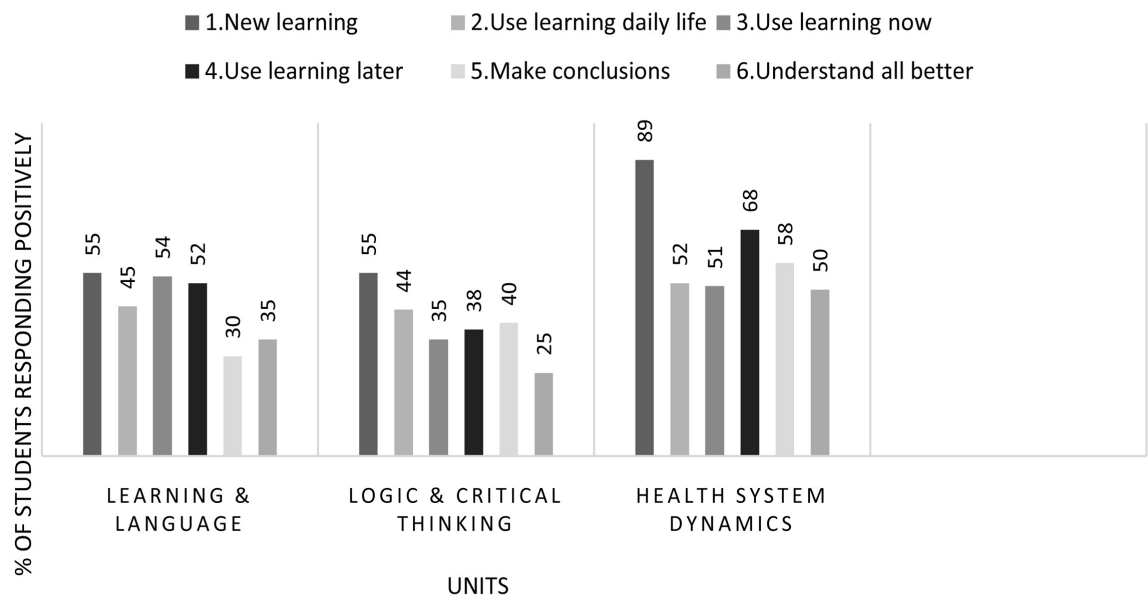

Figure 2. Student feedback on units at mid-term.

With reference to Figure 2, students encountered new learning in all the three sections of the course. However, they rated "Health System Dynamics" more positively in all aspects of the feedback. Almost $90 \%$ found "Health System Dynamics" to be new learning and about $68 \%$ felt they would use the learning later on in their studies. This was a higher rating compared to about $50 \%$ who found "Learning and Language" and "Logic and Critical Thinking" useful.

By the end of Semester 2 all the units of the course had been presented and students were asked to give feedback using the following modified rubric-again asking for a "yes/no" rating (Table 2).

The results for students giving a rating of "yes" were as follows (Figure 3: Student feedback at year end).

Figure 3 shows that "Health Systems Dynamics" still received high ratings (99\%) and two new units "Medical Terminology" (100\%) and "Integrating Problems" (96\%) were also highly rated. Almost all students encountered new learning in these units. "Learning and Language" (61\%) and "Logic and Critical Thinking" (79\%) still received lower ratings compared to the other units. A comparison of ratings for equivalent statements in the two sets of student feedback is given in Table 3. In this table the average score for comparable statements in the two surveys is given. 
Table 2. Modified rubric.

\section{Feedback statement}

1) I have learnt some new things that I did not know before.

2) I will use what I learnt in other units and courses of this year.

3) I will use what I learnt in my further studies next year.

4) What I have learnt from this unit will help me draw conclusions from facts.

5) What I have learnt in this unit will help me understand all the other subjects in this year and later years.

6) My way of thinking and approaching problems has changed this year.

Table 3. Comparison of student mid-term and year-end "yes" ratings.

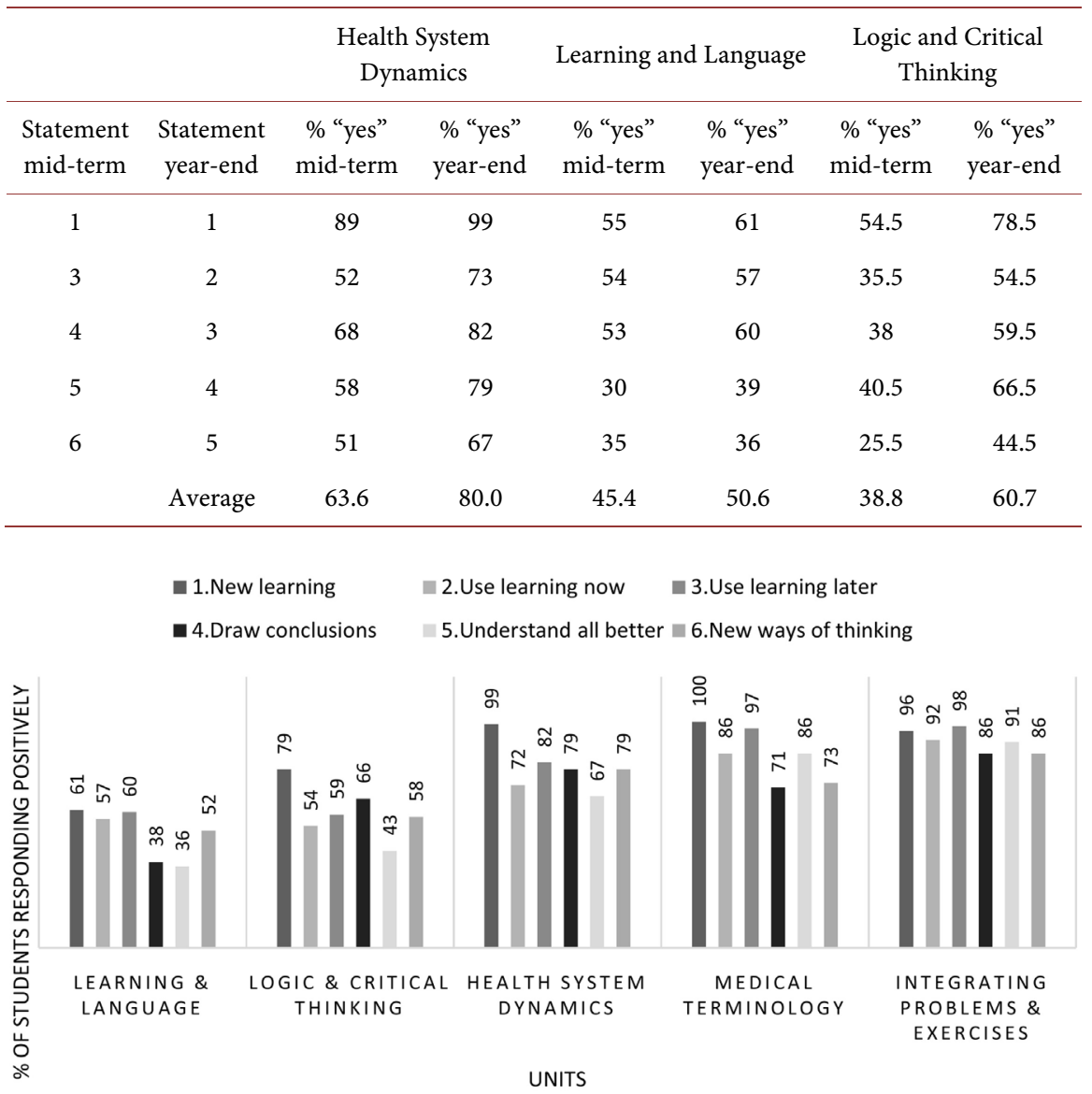

Figure 3. Student feedback at year end.

The scores for equivalent questions improved from those at mid-term-especially for "Logic and Critical Thinking" signifying an improvement proportion of 56\%. "Health System Dynamics" (which was already rated highly) also showed a proportion of improvement of $26 \%$. Little change was observed in "Learning and Language" (11\% proportion of improvement) but this was to be expected-as mentioned before this unit was designed specifically to cater for students who spoke English as a second language. 


\subsection{Students' Experiences 4 and 5 Years after Course Introduction}

In a subsequent qualitative study on students' experiences of integrative learning, 25 students and 10 teachers shared their perceptions on the course "Medical Thought and Practice" [16] [32]. The experiences were summed up in four main themes: lifelong skills, promotion of vertical and horizontal integration, integration as deliberate activity and role of the teacher in integration. It was found that students who experienced the course in the first two years of study were still applying the skills gained in later years, suggesting retention of learning. Students reported experiencing different perceptions of and approach to problem solving as they developed a more enquiring mind. Representative quotes follow:

So, as I was saying that with Health Systems Dynamics with Medical Thought and Practice the basis of how I was taught to approach questions and stuff, those things still haven't left me... [ $4^{\text {th }}$ year student].

...the skills that we have developed through those subjects have, I think, made us into people who think differently about problems and approach problems differently... we now question more and when we get just given a problem or a lecturer says something, we will say “But why?" ... [2 $2^{\text {nd }}$ year student].

... it was very helpful and ... even now the Logic \& Critical Thinking lectures because even now when we're chilling with guys someone will say something that's not making sense ... we say "there is no logic in it" $\ldots\left[5^{\text {th }}\right.$ year student $]$.

Other students felt that the course promoted integrative learning-vertical and horizontal. A specific example given was Medical Terminology which made it easier to understand the meaning of words in subjects like Anatomy and Physiology by putting together components of long medical words to understand their meaning.

...I know last year, what did help was if you did Medical Terminology ... there is a lot of Anatomy that has Latin names and stuff, that was interesting because you could work out what something did... it helps a lot... [ $2^{\text {nd }}$ year student].

Other students commented on how the course practically helped them to learn to integrate, noting that it made a deliberate effort to promote integrative learning by presenting them with opportunities to do so:

...there was a project we did in MTP last year that was really helpful. That was the time we actually started talking about the integration with my friends... where we like have a session where we just talk about integration... [ $2^{\text {nd }}$ year student].

...I have to commend the MTP as far as that is concerned because all... Medical Terminology, Integrating Exercises, HSD and Logic \& Critical Thinking, all of them work to integrate all our subjects together... When we get things like graphs, especially it was very helpful in Physics and Chemistry, a lot of those concepts, integrated so perfectly with HSD... [ $3^{\text {rd }}$ year student].

I find the integrating lectures very useful to integrating information... they give you almost a new perspective sometimes on looking at it and two things 
that you thought might be totally unrelated, they can put them together in such a way that you are able to say... "I understand this now and how it works" ... $\left[3^{\text {rd }}\right.$ year student].

There were experiences relating to an appreciation of the role of the teacher in teaching students to integrate learning.

...honestly for me the best way for me to learn sometimes is not just hearing about the concept but to see it put into action. So, when I see how the integration is actually done, it opens my eyes to the possibilities ... to links that may exist to other subjects... [ $2^{\text {nd }}$ year student].

From the experience of a teacher, students who come from disadvantaged backgrounds will struggle with integration of learning, and that, the course could remedy that.

...the learning background of the learner ...umm... will make a significant contribution to their ability to integrate effectively... I think that students who come from a disadvantaged background ...umm... have got umm... a severe disadvantage in terms of integration ... [Teacher].

...I think that having these opportunities to integrate... at an earlier level in the university system... it would play out in them being able to do it effectively... [Teacher].

Some students also had negative perceptions of the course, since it encouraged integration which was perceived to be increasing the workload; others also did not appreciate its relevance.

...integration would be extra studying... [ $5^{\text {th }}$ year student $]$.

...sometimes you will be studying something and you think "I am never going to use this as a doctor", so you struggle to see the importance of it so it makes you not to take it as seriously... [ [ ${ }^{\text {st }}$ year student $]$.

While not so comprehensive, the quotations above indicate that the "Medical Thought and Practice" course did benefit some students as intended.

We would have liked to give evidence beyond student satisfaction to demonstrate the effect of the course in meeting its two main objectives, by gathering evidence from student study activities and academic performance (Kirkpatrick levels 3 and 4, "Behaviour" and "Results") [42]. We think however that there is a strong internal logic to each of the units, in terms of its being likely to enhance higher level cognitive skills and/or promote the ability to integrate learning from different subjects.

\section{Discussion and Lessons Learnt}

This paper presented a five-pronged, spiralling, examinable course that was explicitly designed to address integrative learning for a diverse student body in medical education. Each of the five components of the course was designed to address specific approaches to preparing students for integrative learning. Reading with comprehension enhances critical thinking skills, problem solving skills and the ability to identify links between subjects; systems thinking enhances an un- 
derstanding of how related events interact; mastering concepts of formal logic guards against false associations; learning Latin and Greek roots of scientific terminology enhances learning with understanding and uncovers links between disciplines; and practical integration exercises increase the ability to integrate. Together these strands of the Medical Thought and Practice course focused on teaching students to understand concepts and link content from different subjects horizontally and vertically.

Students rated the "Medical Thought and Practice" course more highly at the end of the year than at mid-term. The value of the units in the course seems to have become clearer to them as time went by. "Health Systems Dynamics", "Medical Terminology" and "Integrating Exercises" received the highest ratings and the rationale could be attributed to the nature of the units: there was a clear link to the practice of medicine hence students identified the relevance to their studies. While initially less valued, the ratings for the "Logic and Critical Thinking" unit increased dramatically-a very interesting finding that may have its roots in students' initial belief that they knew how to "do" logic anyway and subsequently learnt that they actually do not. The "Learning and Language" unit was the least appreciated by the body of students overall. In implementing this course, which was designed to address student diversity, it became clear that some students had greater need of this unit than others, depending on their background relating to their mother tongue and the quality of their secondary schooling. Our experiences and observations were that this unit benefitted primarily those students who were from a disadvantaged socio-economic and educational background, hence with weaker educational preparation for a university level medical programme.

The data from the phenomenographic study help to clarify the ways in which the units of the course benefited students-sometimes in ways which seem surprising, relating to life outside the medical school. In a following publication these data will be presented and analysed in more detail.

Although the teachers perceived the need for students to take the course, it seems the low ratings for the "Learning and Language" unit were due to "unconscious incompetence" that led to the perception that some units were not useful. There is a need to institute interventions that overcome the perceived stigmatisation of students who need components that are not universally needed. Another observation was that students perceived the course as introducing extra work rather than assisting with learning. This could be a result of the novel content and structure of the course and the fact that it was formally assessed. Integration of learning is a student activity that requires students to reflect on their learning and identify links, and students whose main experience of learning was through lectures perceived this as extra work. The new course also required securing the support of teachers and this took time.

The limitations of this study are that students' feedback on the integrative course reports on single cohorts in the first and second years of the medical programme. These are very useful perspectives as students adjust to a new way of 
learning at the university. Feedback from cohorts in subsequent years would establish whether these experiences change over time.

\section{Next Steps}

The innovation has been in operation for ten years so there is need to obtain feedback from cohorts in subsequent years of the programme to establish whether experiences would have been different. In addition, evaluation of the whole innovation would be beneficial in determining which aspects were of more value than the others.

\section{Conclusion}

This paper demonstrated a unique five-pronged initiative that addresses fundamental issues that have received little attention in undergraduate medical programmes-despite compelling evidence of the heterogeneity of students' entry levels in the language of instruction, critical thinking and problem-solving skills. Assisting students from diverse backgrounds to cope better with their studies and bringing integration of learning to the focus of their learning is a necessary and logical project.

\section{Conflicts of Interest}

The authors declare that they have no financial conflict of interest. The corresponding author was the course coordinator for the innovation described in the paper. The co-author was the supervisor of the corresponding author.

\section{Ethics Approval}

Some of the findings shared in this study emanate from a $\mathrm{PhD}$ study with ethics approval from the Human Research Ethics Committee (Medical) at the University of the Witwatersrand. The ethics approval number is: M110471.

\section{Availability of Data and Material}

Relevant references have been provided. We have not used data that requires additional permission from the original authors.

\section{Authors' Contributions}

The corresponding author conceptualized the idea for this paper and wrote up the first draft. The co-author reviewed the draft and made significant contributions to its improvement.

\section{References}

[1] Rubin, P. and Franchi-Christopher, D. (2002) New Edition of Tomorrow's Doctors. Medical Teacher, 24, 368-369. https://doi.org/10.1080/0142159021000000816

[2] Health Professions Council of South Africa (2014) Core Competencies for Undergraduate Students in Clinical Associate, Dentistry and Medical Teaching and 
Learning Programmes in South Africa. HPCSA, Pretoria, 2.

https://www.hpcsa-blogs.co.za/wp-content/uploads/2017/04/MDB-Core-Competen cies-ENGLISH-FINAL-2014.pdf

[3] Mayet, R. (2016) Supporting At-Risk Learners at a Comprehensive University in South Africa. Journal of Student Affairs in Africa, 4, 1-12.

[4] Ngcobo, S., Ndaba, N., Nyangiwe, B., Mpungose, N. and Jamal, R. (2016) Translanguaging as an Approach to Address Language Inequality in South African Higher Education: Summary Writing Skills Development. Critical Studies in Teaching and Learning, 4, 10-27.

[5] Van der Merwe, J.C. and Van Reenen, D. (2016) Transformation and Legitimation in Post-Apartheid Universities. Sun Media, Bloemfontein.

https://doi.org/10.18820/9781920382612

[6] Chipamaunga, S.R. (2015) How Students Develop the Ability to Integrate Learning-A Phenomenographic Study. PhD Thesis, University of the Witwatersrand, Johannesburg.

[7] Kelly, S. (2007) Classroom Discourse and the Distribution of Student Engagement. Social Psychology of Education, 10, 331-352.

https://doi.org/10.1007/s11218-007-9024-0

[8] Singaram, V.S., Dolmans, D., Lachman, N. and Van der Vleuten, C.P.M. (2008) Perceptions of Problem-Based Learning (PBL) Group Effectiveness in a Socially-Culturally Diverse Medical Student Population. Education for Health, 21, 116.

[9] Makoni, M. (2016) Global Summit on Student Affairs and Services: Prof. Adam Habib's Keynote. Journal of Student Affairs in Africa, 4, 61-64.

[10] Dyrbye, L.N., Thomas, M.R. and Shanafelt, T.D. (2005) Medical Student Distress: Causes, Consequences, and Proposed Solutions. In: Mayo Clinic Proceedings, Elsevier, 1613-1622. https://doi.org/10.4065/80.12.1613

[11] Badat, S. (2010) The Challenges of Transformation in Higher Education and Training Institutions in South Africa. Development Bank of Southern Africa.;8.

[12] Lawrence, J. (2005) Addressing Diversity in Higher Education: Two Models for Facilitating Student Engagement and Mastery. Proceedings of the 28 th HERDSA Annual Conference: Higher Education in a Changing World (HERDSA 2005), Sydney, 3-6 July 2005, 243-252.

[13] Kelly, W.E. (2003) No Time to Worry: The Relationship between Worry, Time Structure, and Time Management. Personality and Individual Differences, 35, 1119-1126. https://doi.org/10.1016/S0191-8869(02)00322-7

[14] Bleakley, A. (2006) Broadening Conceptions of Learning in Medical Education: The Message from Teamworking. Medical Education, 40, 150-157.

https://doi.org/10.1111/j.1365-2929.2005.02371.x

[15] Sfard, A. (1998) On Two Metaphors for Learning and the Dangers of Choosing Just One. Educational Researcher, 27, 4-13. https://doi.org/10.3102/0013189X027002004

[16] Chipamaunga, S. and Prozesky, D. (2019) How Students Experience Integration and Perceive Development of the Ability to Integrate Learning. Advances in Health Sciences Education, 24, 65-84. https://doi.org/10.1007/s10459-018-9850-1

[17] Sehoole, M.T. (2013) Democratizing Higher Education Policy: Constraints of Reform in Post-Apartheid South Africa. Routledge, New York.

https://doi.org/10.4324/9780203959022

[18] Sleeter, C., Torres, M.N. and Laughlin, P. (2004) Scaffolding Conscientization through Inquiry in Teacher Education. Teacher Education Quarterly, 31, 81-96. 
[19] Van de Pol, J., Volman, M. and Beishuizen, J. (2010) Scaffolding in Teacher-Student Interaction: A Decade of Research. Educational Psychology Review, 22, 271-296. https://doi.org/10.1007/s10648-010-9127-6

[20] Shabani, K., Khatib, M. and Ebadi, S. (2010) Vygotsky's Zone of Proximal Development: Instructional Implications and Teachers' Professional Development. English Language Teaching, 3, 237-248. https://doi.org/10.5539/elt.v3n4p237

[21] Brauer, D.G. and Ferguson, K.J. (2015) The Integrated Curriculum in Medical Education: AMEE Guide No. 96. Medical Teacher, 37, 312-322. https://doi.org/10.3109/0142159X.2014.970998

[22] Harden, R.M. (2000) The Integration Ladder: A Tool for Curriculum Planning and Evaluation. Medical Education, 34, 551-557. https://doi.org/10.1046/j.1365-2923.2000.00697.x

[23] Malik, A.S. and Malik, R.H. (2011) Twelve Tips for Developing an Integrated Curriculum. Medical Teacher, 33, 99-104. https://doi.org/10.3109/0142159X.2010.507711

[24] Muller, J.H., Jain, S., Loeser, H. and Irby, D.M. (2008) Lessons Learned about Integrating a Medical School Curriculum: Perceptions of Students, Faculty and Curriculum Leaders. Medical Education, 42, 778-785. https://doi.org/10.1111/j.1365-2923.2008.03110.x

[25] Huber, M.T. and Hutchings, P. (2004) Integrative Learning: Mapping the Terrain. The Academy in Transition. Association of American Colleges and Universities, Washington DC.

[26] Bharuthram, S. (2012) Making a Case for the Teaching of Reading across the Curriculum in Higher Education. South African Journal of Education, 32, 205-214. https://doi.org/10.15700/saje.v32n2a557

[27] Hermida, D. (2009) The Importance of Teaching Academic Reading Skills in First-Year University Courses. https://doi.org/10.2139/ssrn.1419247

[28] Brantmeier, C. (2002) Second Language Reading Strategy Research at the Secondary and University Levels: Variations, Disparities, and Generalizability. The Reading Matrix, 2, No. 3.

[29] Hellekjaer, G.O. (2009) Academic English Reading Proficiency at the University Level: A Norwegian Case Study. Reading in a Foreign Language, 21, 198-222.

[30] Klein, J.T. (2005) Integrative Learning and Interdisciplinary Studies. Peer Review, 7, 8-10.

[31] Newble, D.I. and Entwistle, N.J. (1986) Learning Styles and Approaches: Implications for Medical Education. Medical Education, 20, 162-175. https://doi.org/10.1111/j.1365-2923.1986.tb01163.x

[32] Marton, F. and Booth, S. (1997) Learning and Awareness. Routledge, Mahwah.

[33] Jama, M.P. (2016) Academic Guidance for Undergraduate Students in a South African Medical School: Can We Guide Them All? Journal of Student Affairs in Africa, 4, 13-24.

[34] Rubin, D.M., Richards, C.L., Keene, P.A., Paiker, J.E., Gray, A.R.T., Herron, R.F., et al. (2012) System Dynamics in Medical Education: A Tool for Life. Advances in health Sciences Education, 17, 203-210. https://doi.org/10.1007/s10459-010-9237-4

[35] Bynum IV, W.E. and Goodie, J.L. (2014) Shame, Guilt, and the Medical Learner: Ignored Connections and Why We Should Care. Medical Education, 48, 1045-1054. https://doi.org/10.1111/medu.12521

[36] Lederman, N.G. (1999) Teachers' Understanding of the Nature of Science and 
Classroom Practice: Factors That Facilitate or Impede the Relationship. Journal of Research in Science Teaching, 36, 916-929.

https://doi.org/10.1002/(SICI)1098-2736(199910)36:8<916::AID-TEA2>3.0.CO;2-A

[37] Kukla, A. (2000) Social Constructivism and the Philosophy of Science. Psychology Press, London.

[38] Facione, N.C. and Facione, P.A. (2008) Critical Thinking and Clinical Judgment. Critical Thinking and Clinical Reasoning in the Health Sciences: A Teaching Anthology. Insight Assessment/The California Academic Press, Millbrae, 1-13.

[39] Bosman, J.P., Kritzinger, J.P.K., Meiring, J.H., Schumann, C.J., Abrahams, P.H. and Greyling, L.M. (2006) Medical Terminology for Students of the Health Professions. Van Schaik, Pretoria.

[40] Jóskowska, K. and Grabarczyk, Z. (2013) Greek and Latin in Medical Terminology. Medical Research Journal, 1, 41-52.

[41] Hmelo-Silver, C.E. (2004) Problem-Based Learning: What and How Do Students Learn? Educational Psychology Review, 16, 235-266.

https://doi.org/10.1023/B:EDPR.0000034022.16470.f3

[42] Kirkpatrick, J.D. and Kirkpatrick, W.K. (2016) Kirkpatrick's Four Levels of Training Evaluation. Association for Talent Development, Alexandria. 